\title{
ANÁLISE TÉCNICA E ESTIMATIVAS DE CUSTOS DE INVENTÁRIO DE PROSPECÇÃO EM UMA FLORESTA ESTACIONAL SEMIDECIDUAL SUBMONTANA ${ }^{1}$
}

Lucas José Mazzei de Freitas ${ }^{2}$, Agostinho Lopes de Souza ${ }^{3}$, Helio Garcia Leite ${ }^{3}$ e Márcio Lopes da Silva ${ }^{3}$

\begin{abstract}
RESUMO - Dentre as atividades que compõem um sistema de manejo florestal, a colheita é a mais dispendiosa e, quando realizada sem planejamento, acarreta sérios danos à estrutura da floresta. Para uma exploração de baixo impacto, isto é, para minimizar os danos à regeneração natural e às árvores remanescentes, é obrigatório realizar levantamento detalhado da área a ser manejada. O objetivo principal deste trabalho foi propor uma metodologia de inventário de prospecção com mapeamento arbóreo. Em uma unidade de produção anual de 24,25 ha, foram inventariados 2.707 indivíduos arbóreos, com DAP $\geq 20 \mathrm{~cm}$, que, além das características quantitativas e qualitativas, tiveram as suas coordenadas (UTM) determinadas e arquivadas em um banco de dados georreferenciados. As análises do inventário de prospecção englobaram a viabilidade técnica e a determinação do custo do método proposto. A metodologia, com base na utilização de equipamento digital de medição de distância, mostrou-se exequível. O rigor exigido na determinação da localização das árvores, assim como as características de relevo, sub-bosque denso e grande infestação de cipós, influenciou no rendimento do inventário de prospecção, que foi de $442 \mathrm{~m}$ por dia para a abertura de picadas e de 0,80 ha por dia para a realização do inventário de prospecção. O custo da abertura de picadas e do inventário de prospecção foi de US\$35,69/ ha e US\$89,43/ha, respectivamente.
\end{abstract}

Palavras-chave: Floresta Atlântica, floresta estacional semidecidual submontana, manejo florestal, inventário de prospecção e enumeração completa.

\section{TECHNICAL ANALYSIS AND COSTS ESTIMATES OF A COMPLETE ENUMERATION FOREST INVENTORY OF A SUBMONTANE SEMIDECIDUOUS SEASONAL FOREST}

\begin{abstract}
Among the activities which compose a forest management system, harvest is the most expensive one, and when it is carried out without planning it causes severe damages to the forest structure. To perform low impact exploitation, that is, to minimize damages to natural regeneration and remaining trees, a detailed survey of the area to be managed must be done. The main objective of this work was to propose a new methodology of prospection survey with an arboreous mapping. In a unit of annual production of 24.25 ha, 2,707 arboreous individuals were surveyed, with $\mathrm{DBH} \geq 20 \mathrm{~cm}$, and their data of quantitative and qualitative features, besides their geographic coordinates (UTM) were kept in a geographic referred database. The prospection survey analyses included the technical viability and the determination of cost of the proposed method. The prospection survey methodology, based on the use of digital equipment for distance measurement, showed to be technically
\end{abstract}

\footnotetext{
${ }^{1}$ Recebido em 17.07.2003 e aceito para publicação em 25.11.2004.

${ }^{2}$ 172, Square de Corte bât 7 esc. 59 ap. 490. 34080. Montpellier França.

${ }^{3}$ Departamento de Engenharia Florestal da UFV.36571-000. E.mail:<als@ufv.br>, <hgleite@ufv.br $>$ e $<$ marlosil@ufv.br $>$.
} 
feasible. The accuracy required in the determination of the position of the trees, as well as the relief conditions, dense understory and great presence of vines, influenced directly the prospection survey outcome, which were of $442 \mathrm{~m}$ per day for trail openings, and of 0.80 ha per day for the prospection survey carried out. The cost of trail opening and prospection survey were of US\$35.69 and US\$89.43 per hectare, respectively.

Key-words: Atlantic Forest, submontane semideciduous seasonal forest, forest management, prospection survey, and complete enumeration forest inventory.

\section{INTRODUÇÃO}

O manejo de florestas tropicais, sobretudo para a produção sustentada de madeira, deve ser disciplinado. O inventário de prospecção é a ferramenta pela qual são obtidas informações precisas sobre as árvores e os talhões ou unidades de trabalho a serem colhidos. A abertura de carreadores, a localização exata de cada árvore comercial e a sua direção de queda, os prováveis danos à floresta remanescente e quais as árvores devem ser retidas como matrizes ou reservadas para uma futura colheita são exemplos dessas informações. Este inventário, diferentemente dos tradicionais inventários por amostragem, é a enumeração completa de todos os indivíduos de tamanho comercial e pré-comercial que ocorrem em uma área. É uma das atividades do manejo florestal de mais elevada importância, já que a maioria das atividades pré-exploratórias e de exploração é planejada e executada de acordo com as informações geradas pelo inventário de prospecção.

O inventário de prospecção contribui para a diminuição dos desperdícios das operações de exploração (AMARAL et al., 1998). É uma atividade que proporciona informações para a administração da floresta, sobretudo para o planejamento e execução da exploração de impacto reduzido, sendo, inclusive, uma atividade obrigatória nos planos de manejo florestal sustentável de uso múltiplo na Amazônia Legal (IBAMA, 2002).

Dentre os principais resultados de pesquisas em manejo e exploração florestal realizadas durante os últimos 15 anos pela EMBRAPA, na seqüência de operações para um sistema silvicultural policíclico encontram-se o inventário florestal a $100 \%$ de intensidade e a preparação de mapas de exploração, dois anos antes da colheita (EMBRAPA-CPATU, 1991).

Alguns exemplos de metodologias para a realização do inventário de prospecção e os rendimentos dessa operação em floresta ombrófila densa - domínio
Amazônico - podem ser consultados em SUDAM (1978), FUPEF (1983), Machado (1988), Bodegon e Graaf (1994), Barros e Veríssimo (1996) e Amaral et al. (1998).

Os objetivos deste trabalho foram verificar a viabilidade técnica e analisar os custos de execução do inventário de prospecção em uma Floresta Estacional Semidecidual Submontana - domínio Atlântico.

\section{MATERIAL E MÉTODOS}

\subsection{Caracterização da área de estudo}

Oexperimento foi realizado na Fazenda Paciência $\left(21^{\circ}\right.$ 51' 13" de latitude sul e 43 16' 27" de longitude oeste), situada no município de Matias Barbosa, MG (Figura 1). Na propriedade está sendo executado um Plano de Manejo Florestal de Rendimento Sustentado (PMFRS), cujo objetivo é a produção de madeira para serraria e carvão. A altitude média da propriedade é de 600 $\mathrm{m}$. O clima da região é classificado como mesotérmico ou Cwa, na classificação de Köppen, apresentando inverno seco e verão quente e chuvoso. A média anual das precipitações pluviométricas da região é de aproximadamente $1.500 \mathrm{~mm}$, sendo estas concentradas entre os meses de novembro e março. A temperatura média anual é de $18,7^{\circ} \mathrm{C}$ (GOMES et al., 2004).

A cobertura vegetal é de Floresta Estacional Semidecidual Submontana. Da área total da propriedade, cerca de 510 ha são cobertos por florestas em estágio secundário de regeneração. Nos altos de morros e nas áreas de difícil acesso, encontram-se os maiores indivíduos e as matas mais estocadas. Nas encostas de morros e áreas antes ocupadas por lavouras de café e pasto, situam-se florestas em estágio inicial de regeneração, sendo formadas por árvores baixas, espaçadas, com grande infestação de cipós e com a presença de gramíneas. 


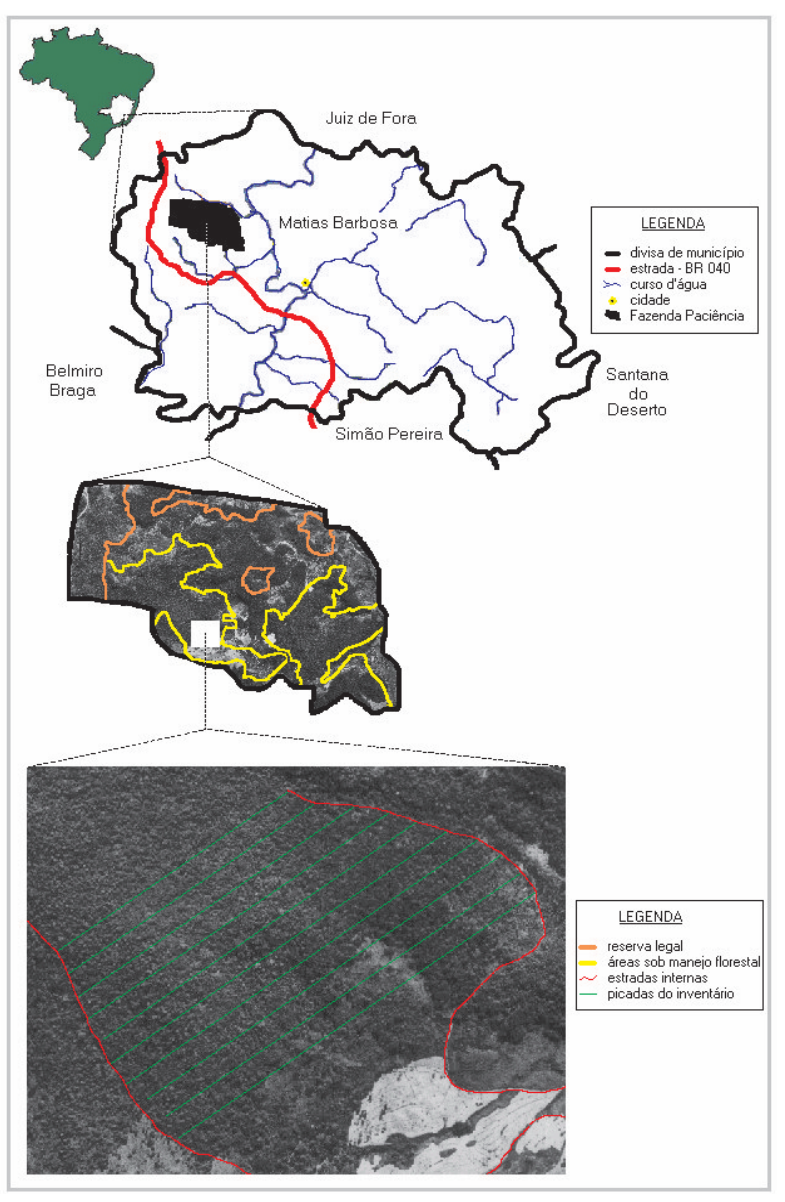

Figura 1 - Localização geográfica do município de Matias Barbosa, MG, da fazenda Paciência, do talhão de exploração no 8 e das picadas do inventário de prospecção.

Figure 1-Geographic location of the municipality of Matias Barbosa, MG, Brazil, of the Paciencia Farm, with no. 8 logging stand and the prospection survey trails.

\subsubsection{Inventário e coleta de dados}

Dos 510 ha de ocorrência da Floresta Estacional Semidecidual Submontana, 291 ha foram selecionados para a execução do PMFRS, pelo fato de não apresentarem restrição de uso legal. Uma vez que o ciclo de corte especificado na Portaria IEF-MG no 054 (MINAS GERAIS, 1997) é de 12 anos, a área foi subdividida em talhões de colheita anual de 24,25 ha. O inventário de prospecção foi realizado no talhão $\mathrm{n}^{\circ} 8$, que seria explorado no ano de 2001.

\subsubsection{Inventário de prospecção}

Seguindo as recomendações de inventários de prospecção (SUDAM, 1978; FUPEF, 1983; BODEGON e GRAAF, 1994), o talhão (Figura 1) foi subdividido em setores de inventário de $40 \mathrm{~m}$ de largura e comprimento variável, de acordo com a geometria da área.

Foram abertas picadas de 1 a $2 \mathrm{~m}$ de largura, eqüidistantes em $40 \mathrm{~m}$ e orientadas paralelamente à picada delimitadora do talhão. Para balizar as medições, a cada $30 \mathrm{~m}$, ao longo de cada picada, foi cravado um piquete de madeira de 1,2 m de altura e pintado de amarelo. No inventário de prospecção, utilizou-se hipsômetro digital Vertex da marca Forestor, que trabalha com pulsos ultra-sônicos e é composto por duas unidades: o instrumento medidor e o transponder emissor dos sinais. O referido instrumento foi usado, simultaneamente, como hipsômetro e distanciômetro e, sobretudo, permitiu obter as leituras da declividade das picadas, as coordenadas e as alturas total e comercial das árvores mapeadas $(D A P \geq 20 \mathrm{~cm})$.

Uma trena de $50 \mathrm{~m}$ foi fixada sobre a picada (eixo y) e utilizada para a medição das coordenadas da árvore a ser mapeada. O líder da equipe se deslocava pela picada munido com o instrumento medidor. $\mathrm{O}$ mateiro localizava a árvore a ser mapeada e encostava o transponder no tronco. O líder, posicionado sobre a picada e em ângulo reto com a árvore a ser mapeada, tendo a trena como referência, media e anotava a coordenada y. Nessa mesma posição, o líder apontava o aparelho medidor para o transponder e fazia a medição da distância da árvore em relação à picada (coordenada $x$ ). Seguindo essa metodologia de inventário $100 \%$, mapeavam-se todas as árvores com DAP $\geq 20 \mathrm{~cm}$ que se encontravam a uma distância de até $20 \mathrm{~m}$ de ambos os lados da picada, coletando-se todos os dados referentes à árvore mapeada e os repassando para o líder, que os registrava na ficha de coleta de dados de campo e, após ratificar as informações coletadas, dava prosseguimento ao inventário prospectivo. Ao final de cada picada, a equipe movia-se para a picada seguinte e executava a mesma rotina de trabalho, e assim sucessivamente até completar a última picada do talhão.

\subsection{Dados coletados}

As seguintes informações foram coletadas de cada árvore mapeada: localização da árvore no 
talhão (coordenadas $x$ e y), identificação arbórea, diâmetro à altura do peito $(D A P)$, altura total $(H t)$, altura comercial $(H c)$, qualidade do fuste $(Q f)$, defeitos no tronco $(D f)$, qualidade da copa $(Q c)$, iluminação da copa (Ic), inclinação natural do tronco (In) e infestação por cipós $(\mathrm{Ci})$.

Os critérios de avaliação do grau de aproveitamento do fuste (AMARAL et al., 1998) foram: $Q f=1$, tronco de boa qualidade, indivíduo que apresenta de 80 a $100 \%$ de aproveitamento do tronco; $Q f=2$, regular, indivíduo com aproveitamento do tronco entre 50 e $79 \%$; e $Q f=3$, inferior, indivíduo com menos de $50 \%$ de aproveitamento do tronco.

Os fustes também foram avaliados e classificados nas seguintes classes de defeito (SILVA e LOPES, 1984): $D f=1$, nenhum defeito aparente; $D f=2$, suspeita de defeitos; $D f=3$, oco aparente; $D f=4$, podridão; e $D f=5$, rachaduras.

Quanto à copa, as avaliações incluíram o grau de iluminação e qualidade da copa (SILVA e LOPES, 1984). O grau de iluminação incluiu as classes: $I c=1$, iluminação total, refere-se a árvores dominantes de copas emergentes que recebem luz solar direta; $I c=2$, iluminação parcial, algumas partes da copa recebem luz direta, porém outras se apresentam sombreadas por vizinhas; e $I c=3$, sombra, a copa não recebe luz solar direta, recebendo apenas luz difusa. Para avaliar a qualidade da copa foram adotadas as seguintes classes: $Q c=1$, boa, copa inteira e bem distribuída em torno do eixo central da árvore; $Q c=2$, regular, copa com alguns galhos quebrados e com galhos mortos; e $Q c=3$, inferior, copa incompleta, mais da metade dos galhos quebrados.

A infestação por cipós englobou as classes seguintes (SILVA e LOPES, 1984): $C i=1$, árvore livre de cipós; $C i=2$, árvore com cipós apenas no tronco; $C i=3$, árvore com cipós apenas na copa; e $C i=4$, árvore com cipós no tronco e na copa.

E, por último, a inclinação natural da árvore foi avaliada da seguinte forma (AMARAL et al., 1998): In $=1$, ampla, árvore sem inclinação natural, a derrubada pode ser direcionada a todas as posições; $I n=2$, intermediária, árvore com tronco reto, porém com copa mal distribuída, direcionamento da queda com alguma restrição; e In = 3, limitada, árvore com tronco inclinado, impossível direcionar a sua queda.

A cada $30 \mathrm{~m}$ foi medida a declividade das picadas. Características intrínsecas do talhão, como presença de cursos d'água e vertentes, áreas cipoálicas, árvores caídas, afloramentos rochosos e mudanças bruscas no relevo do talhão, também foram anotadas na planilha de campo.

\subsection{Análise da viabilidade técnica operacional do inventário de prospecção}

As variáveis utilizadas para avaliar o rendimento das operações do inventário a $100 \%$ foram:

a) Horas efetivas de trabalho por dia: refere-se ao tempo gasto durante a atividade de inventário, excluindo paradas para o almoço ou devido a acidentes. Foi utilizado um cronômetro, que era ativado no início das atividades, desligado durante o almoço e ativado novamente até o fim das atividades do dia de trabalho; b) hectares por dia: refere-se à área inventariada durante um dia de trabalho; e c) hectares por homem por dia: refere-se à área inventariada durante o dia de trabalho, dividida pelo número de pessoas (03) que fizeram parte da equipe.

\subsection{Determinação dos custos do inventário de prospecção}

Para análise da viabilidade econômica, a variável comparativa foi o custo de inventário de prospecção, incluindo as atividades de abertura de picadas, por hectare. Os custos são apresentados em dólares americanos, para analogias com outros métodos de inventário a $100 \%$.

\subsubsection{Depreciação}

A depreciação corresponde à perda do valor dos equipamentos com o passar do tempo e uso. Foi utilizado o método de depreciação linear (FARO, 1979; HIRSCHFELD, 1992; BARROS e VERÍSSIMO, 1996; VERÍSSIMO et al., 1996):

$$
D_{h}=\frac{V c-V r}{n \times h}
$$

em que: $D_{h}$ é a depreciação do equipamento por horas de trabalho; $V c$ é o valor de compra do equipamento, incluindo impostos e taxas em dólares americanos; $\mathrm{Vr}$ é o valor de revenda do equipamento, ou seja, $20 \%$ de $V c ; n$ é a vida útil em anos; e $h$ são as horas efetivas de uso anual.

A depreciação calculada por essa fórmula retorna o custo da hora efetiva de trabalho, mas, como os custos 
foram calculados em função do hectare de floresta inventariada, foi utilizada a seguinte fórmula:

$$
D_{h a}=\frac{V c-V r}{n \times h a_{a n o}}
$$

em que: $D_{h a}$ é a depreciação do equipamento por hectare de trabalho, e $h a_{\text {ano }}$ é a quantidade de hectares possíveis de serem inventariados por ano, ou seja, a quantidade de hectare inventariado em um dia (rendimento) multiplicada pelos dias de trabalho em um ano. Para o cálculo do número de dias de trabalho em um ano, foram multiplicados os dias de trabalho de um mês (22 dias) pelos 12 meses do ano.

Os seguintes equipamentos tiveram a sua depreciação estimada e fizeram parte do material utilizado na realização do inventário: trena, bússola, hipsômetro Vertex Forestor, podão, foice, facão, martelo e canivete.

Embora não seja usual calcular a depreciação de materiais, e sim para bens de capital, considerou-se que tais materiais teriam uma vida útil de curta duração (2-10 anos) e se enquadrariam no conceito de bens de duração curta (SPEIDEL, 1966).

\subsubsection{Custo de oportunidade ou juros}

O custo de oportunidade foi calculado ao aplicar ao investimento médio anual (IMA) a taxa de juros que seria aplicada ao capital caso tivesse sido investido em outra atividade ou no mercado financeiro, mediante o emprego da seguinte fórmula (FARO, 1979; NAUTIVAL, 1988):

$$
J=\frac{I M A \times i}{h a_{\text {ano }}}
$$

em que: $J$ é o custo de oportunidade por hectare inventariado; $i$ é a taxa de juros do mercado, $12 \%$ a.a.; $h a_{a n o}$ é a quantidade de hectares possíveis de serem inventariados por ano; e IMA é o investimento médio anual, dado pela seguinte fórmula:

$$
I M A=\frac{(V c-V r) \times(n+1)}{2 \times n}+V r
$$

Os equipamentos utilizados no inventário, como material de escritório (prancheta e rotulador) e material de consumo (fita métrica, pincel, lapiseira, caneta, borracha, prego, estacas, lata de tinta, fita do rotulador e fita-crepe) fizeram parte do cálculo do IMA. Da mesma forma como descrito para a depreciação, embora não seja comum a determinação do IMA para material de consumo, o cálculo resultante se equipararia ao investimento fixo anual necessário para a realização do trabalho, uma vez que a vida útil de tais materiais seria de um ano.

\subsubsection{Custo com salários}

O cálculo do custo com salários por hectare $\left(C S_{h a}\right)$ foi calculado, em dólares americanos por hectare, da seguinte forma:

$$
C S_{h a}=\frac{S d}{h a_{d i a}}
$$

em que: $S d$ é a soma dos salários dividida por 22 dias úteis de trabalho por mês; e $h a_{d i a}$ é a quantidade de hectares inventariados em um dia. Na conversão para a moeda americana, foi utilizada a taxa de $1^{\circ}$ de março de 2001, quando US\$1,00 valia R \$2,01. Dessa forma, o valor do salário mínimo e do salário de referência do engenheiro florestal, em março de 2001, era de US $\$ 75,12$ e US\$597,01, respectivamente. Foram somadas aos custos com os salários as despesas relacionadas a Encargos Sociais, Previdência Social, Fundo de Garantia, Seguro Contra Acidentes Pessoais, CONTAG, Salário-Educação, Férias e 13은 Salário. Esses encargos correspondem a $58 \%$ do salário e, apesar de nem sempre serem integralmente pagos, fizeram parte da composição dos custos (VERÍSSIMO et al., 1996). Assim, os custos totais com salários por hectare, $C T S_{h a}$, foram:

$$
C T S_{h a}=C S_{h a}+0,58 \times C S_{h a}
$$

\subsubsection{Custos com alimentação}

Os custos com a alimentação foram estimados pelo uso da seguinte equação (NAUTIVAL, 1988; SILVA et al., 2002):

$$
C A_{h a}=\frac{\text { valor da refeição } \times \text { número de pessoas da equipe }}{h a_{\text {dia }}}
$$

em que: $C A_{h a}$ é o custo com alimentação por hectare, sendo US $\$ 1,24$ o preço da refeição na cidade de Matias Barbosa em março de 2001.

\subsubsection{Custos de administração}

São os custos relacionados com os trabalhos de escritório, contabilidade e finanças e de supervisão de campo (REZENDE e OLIVEIRA, 2001). Neste estudo, 
os custos de administração foram considerados como $10 \%$ sobre os demais gastos.

\subsubsection{Custo total do hectare de inventário de prospecção}

O custo total por hectare, $C T_{h a}$, é, segundo Silva et al. (2002), a soma de todos os custos citados anteriormente:

$$
C T_{h a}=D_{h a}+J+C T S_{h a}+C A_{h a}+\left[10 \%\left(D_{h a}+J+C T S_{h a}+C A_{h a}\right)\right]
$$

em que: $D_{h a}$ é a depreciação do equipamento por hectare de trabalho, $J$ é o custo de oportunidade por hectare inventariado, $C T S_{h a}$ é o custo total com salários por hectare e $C A_{h a}$ é o custo com alimentação por hectare.

\subsubsection{Custo do inventário em relação à produção de madeira}

Este custo foi calculado em função do volume de madeira potencialmente explorável por hectare (GAMA SILVA e BRAZ, 1993), ou seja:

$$
C T_{m^{3}}=\frac{C T_{h a}}{V o l_{h a}}
$$

em que $C T_{m^{3}}$ é o custo do inventário de prospecção por metro cúbico de madeira; e $V o l_{h a}$ é o volume do fuste comercial com casca, por hectare de floresta. Os volumes de cada árvore foram estimados pelas equações volumétricas elaboradas por CETEC (1995):

$$
\begin{aligned}
& \mathrm{VT}_{\mathrm{CC}}=0,000074230 \times D A P^{1,707348} \times H t^{1,16873} \\
& \mathrm{VF}_{\mathrm{CC}}=0,000038857 \times D A P^{1,70764} \times H t^{1,32032}
\end{aligned}
$$

em que: $V T_{C C}$ é o volume total com casca, $V F_{C C}$ é o volume do fuste comercial com casca, $D A P$ é o diâmetro à altura do peito e $H t$ é a altura total.

\section{RESULTADOS E DISCUSSÃO}

\subsection{Análise técnica}

\subsubsection{Abertura das picadas}

Para a realização do inventário de prospecção foram abertos $6,6 \mathrm{~km}$ de picadas, o que consumiu 15 dias de trabalho de uma equipe de três pessoas, com uma média de $442 \mathrm{~m}$ abertos por dia. Em cada dia foram gastos, em média, 4 horas e 59 minutos de trabalho efetivo, o que representou $89 \mathrm{~m}$ de picada aberta por hora.

\section{R. Árvore, Viçosa-MG, v.29, n.1, p.65-75, 2005}

As leituras da declividade da picada, feitas a cada $30 \mathrm{~m}$, mostraram que o talhão apresentava declividade média de $16,4^{\circ}$, com valores entre $46,1^{\circ}$ e $0,1^{\circ}$.

No presente trabalho, constatou-se o que já foi descrito pela FUPEF (1983): em áreas acidentadas, a abertura de picadas acarreta erros, e o trabalho de inventário torna-se difícil; em áreas com muitos cipós, com muitas árvores caídas e, ou, com bambus, tanto a abertura de picadas quanto o caminhamento do pessoal de inventário são difíceis, lentos e onerosos.

Em floresta amazônica, FUPEF (1983) apresentou um rendimento de $7.000 \mathrm{~m}$ de picada aberta por dia, com uma equipe (seis pessoas) formada exclusivamente para essa atividade. Bodegon e Graaf (1994), trabalhando em floresta amazônica no Suriname, com uma equipe de cinco homens, alcançaram um rendimento de 2.500 $\mathrm{m}$ de picada por dia. Para essa mesma fitofisionomia, Amaral et al. (1998) obtiveram um rendimento de 170 $\mathrm{m}$ por hora de serviço com três pessoas envolvidas na abertura de trilhas - um baixo rendimento quando comparado com os outros inventários realizados em Floresta Ombrófila Densa, mas, ainda assim, 91\% superior ao verificado na Floresta Estacional Semidecidual Submontana.

No presente trabalho, vários fatores influenciaram o rendimento do inventário de prospecção: a declividade do talhão, onde áreas íngremes ultrapassavam 45; para a abertura de $30 \mathrm{~m}$ de picada, gastava-se aproximadamente uma hora de serviço; os equipamentos, sobretudo o tipo da bússola utilizada na abertura das picadas; e a baixa visibilidade no interior da mata secundária que comprometia as visadas a distâncias superiores a $20 \mathrm{~m}$. Freqüentemente era necessário transportar os instrumentos e materiais de campo, reinstalar e nivelar a bússola, porque a elevada infestação por lianas, o denso sub-bosque e, em alguns trechos, bambus e afloramentos rochosos dificultavam os deslocamentos, as visadas e as medições das árvores mapeadas. Menciona-se que, exceto o coordenador, nenhum membro da equipe conhecia a metodologia, sobretudo porque o inventário de prospecção não é atividade obrigatória na execução dos planos de manejo no Estado de Minas Gerais (MINAS GERAIS, 1997). Apesar das dificuldades apresentadas, a qualidade do trabalho não foi comprometida. A distância média entre as picadas foi de 40,09 m, com um erro médio entre as picadas de $\pm 2,1 \mathrm{~m}$. 


\subsubsection{Inventário de prospecção}

A equipe de inventário de prospecção assimilou rapidamente a metodologia, e, já no segundo dia de trabalho, as tarefas eram bem desempenhadas. Foram gastos 30 dias de serviço de uma equipe de quatro pessoas. Em um dia foram trabalhados, em média, 4 h 53 min e inventariado 0,80 ha de floresta, com um rendimento de 0,20 ha por homem por dia.

Por não se dispor de resultados de trabalhos científicos relatando experiências com inventário de prospecção em Floresta Estacional Semidecídual Submontana, foi necessário fazer comparações com estudos realizados em tipologias de floresta equatorial de terra firme, onde o estágio sucessional, o tipo de sub-bosque, a declividade do terreno ou, ainda, o diâmetro das árvores inventariadas (potencialmente comerciais, $D A P \geq 45 \mathrm{~cm}$, e pré-comerciais, $35 \leq D A P<45 \mathrm{~cm}$ ) são diferentes. Há os seguintes relatos de rendimentos de inventários de prospecção: 10 a 15 ha/dia, com uma equipe de sete pessoas (FUPEF, 1983); 20 a 25 ha/dia, com uma equipe de cinco pessoas (BODEGON e GRAAF, 1994); e 5,7 ha/dia, com uma equipe de quatro pessoas (COSTA et al., 1999). Menciona-se que, nesses trabalhos, apenas as árvores de espécies desejáveis e acima do diâmetro comercial $(D A P \geq 45 \mathrm{~cm})$ foram inventariadas. Tal seleção faz que somente 16 a 19 árvores por hectare participem efetivamente dos custos do levantamento. As coordenadas X e Y de localização das árvores foram estimadas e as medidas, obtidas a partir da observação dos piquetes distribuídos ao longo das picadas. A maior parte dos trabalhos engloba apenas uma variável de qualificação do fuste, além da identificação arbórea, da determinação da altura, do diâmetro e das coordenadas. E, finalmente, no Sistema Celos de Manejo no Suriname (BODEGON e GRAAF, 1994), o diâmetro é estimado de tal forma que, após a realização do inventário, são recomendadas verificações com suta ou fita métrica (FUPEF, 1983; BODEGON e GRAAF, 1994; COSTA et al., 1999). Os resultados do inventário de prospecção do presente estudo diferem dos apresentados na literatura, provavelmente em razão de tratar-se de uma floresta secundária; a coordenada y foi medida com o auxílio de uma trena e a coordenada $x$, determinada com o distanciômetro; a inclusão de outras variáveis consideradas importantes por Silva e Lopes (1984), Silva (1989), Carvalho (1992) e Amaral et al. (1998), isto é, qualidade e iluminação da copa, grau de infestação de cipós, inclinação natural dos indivíduos arbóreos e defeitos do fuste; e, sobretudo, o diâmetro de inclusão das árvores mapeadas, $D A P \geq 20 \mathrm{~cm}$, o que exigia a avaliação de, em média, 112 árvores por hectare.

Assim como na abertura das picadas, a declividade do terreno e o sub-bosque denso influenciaram o deslocamento da equipe e o rendimento do inventário de prospecção. Verificou-se (Figura 2) relação inversa entre a densidade de árvores por hectare, a declividade média do talhão e a área basal por hectare com o rendimento do inventário, sendo obtida a equação:

$$
\begin{aligned}
\text { Rend }_{\text {ha/h }}= & 0,4756-0,00116 \times \text { Densidade-0,003056 x } \\
& \text { Declividade-0,025 x Área basal }+0,00008378 \\
& \text { x (Densidade } \times \text { Área basal })
\end{aligned}
$$

com $\mathrm{R}^{2}=80,8 \%$.

\subsection{Determinação dos custos}

Os valores dos equipamentos e dos materiais de escritório e de consumo, bem como o investimento médio anual (IMA) e o custo com a depreciação dos equipamentos utilizados, respectivamente, na abertura das picadas e na realização do inventário de prospecção estão descriminados nos Quadros 1 e 2. Verifica-se, no Quadro 1, que na abertura de picadas os itens trena, rotulador, estacas, fita e bússola demandaram $87,5 \%$ do valor de compra e $88 \%$ do IMA. Os itens com vida útil de até um ano representaram $62,2 \%$ do IMA. No inventário de prospecção, constatou-se (Quadro 2) que os itens trena, hipsômetro/distanciômetro, podão, rotulador e fita do rotulador contribuem com $99,7 \%$ do Vc e 99,0\% do IMA. Destacou-se a elevada participação $(91,5 \%)$ do hipsômetro Vertex no IMA. Os itens com vida útil de até um ano representaram somente $1,9 \%$ do IMA.

\subsubsection{Abertura das picadas}

$\mathrm{Na}$ abertura das picadas foram gastos US\$ 35,69/ ha ou, ainda, US $\$ 0,84 / \mathrm{m}^{3}$ de madeira estocada (o talhão de exploração no 8 apresentou uma média de $42,5 \mathrm{~m}^{3} /$ ha de volume estocado). O custo total por hectare foi repartido em custo com juros $(0,01 \%)$, depreciação de equipamentos $(0,12 \%)$, salários $(85 \%)$ e alimentação $(5,9 \%)$. O custo com a administração somou $9,1 \%$, uma vez que este foi calculado em função dos demais custos e não sobre o montante.

R. Árvore, Viçosa-MG, v.29, n.1, p.65-75, 2005 


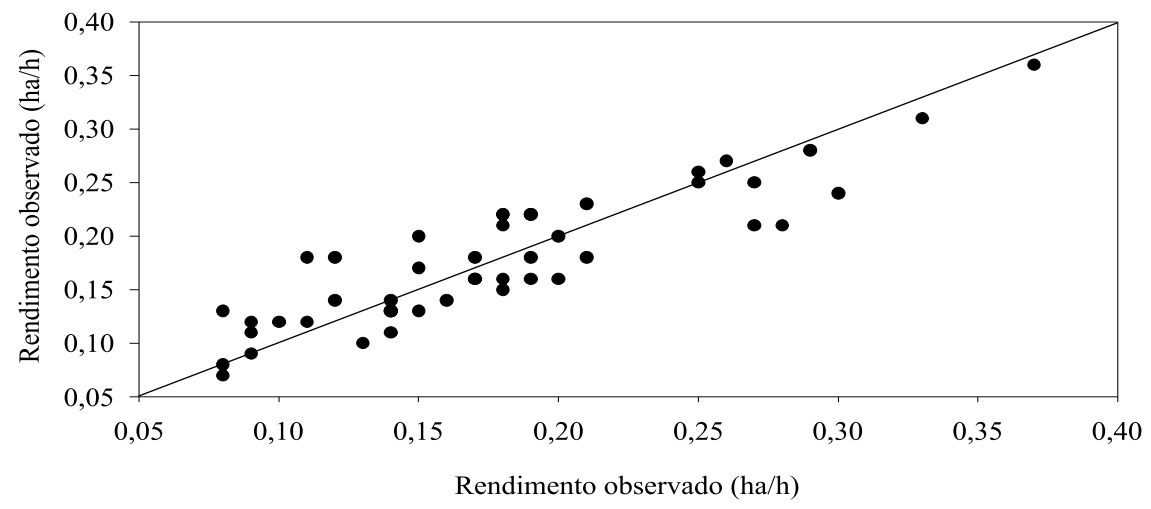

Figura 2 - Relação entre o rendimento (ha/h) observado em campo do inventário de prospecção e o rendimento estimado pela equação: $\operatorname{Rend}_{(\mathrm{ha} / \mathrm{h})}=0,4756-0,00116 \times$ Densidade $-0,003056$ x Declividade $-0,025 \times$ Área Basal $+0,00008378 \times$ (Densidade x Área Basal).

Figure 2 - Relation between the yield ( ha/ha) observed in the field prospection survey and the yield predicted by the equation: Rend $_{(\text {ha } / \mathrm{h})}=0,4756-0,00116 \times$ Density -0,003056 $\times$ Declivity -0,025 x Basal Area +0,00008378 $\times$ (Density $x$ Basal Area).

Quadro 1 - Lista dos equipamentos e do material de consumo utilizados na abertura das picadas no talhão de exploração no 8 , com os respectivos valores de compra $\left(V_{c}\right)$ e revenda $\left(V_{r}\right)$, vida útil $(n)$, depreciação $\left(D_{h a}\right)$ e investimento médio anual (IMA). Valores em US\$

Table 1 - List of the equipment and consumption material used in the trail openings in the no. 8 logging stand, with their respective purchase $(V c)$ and resale $(V r)$ values, shelf life $(n)$, depreciation (Dha) and mean annual investiment (IMA). Values in US\$

\begin{tabular}{|c|c|c|c|c|c|c|c|c|}
\hline Equipamento & Quantidade & Unidade & Preço & $\mathrm{V}_{\mathrm{c}}$ & $\mathrm{n}$ & $\mathrm{V}_{\mathrm{r}}$ & D ha & IMA \\
\hline Trena & 1 & und & 37,00 & 37,00 & 5 & 7,40 & 0,03 & 25,16 \\
\hline Bússola & 1 & und & 12,44 & 12,44 & 5 & 2,49 & 0,01 & 8,46 \\
\hline Foice & 2 & und & 1,49 & 2,99 & 3 & 0,60 & 0,00 & 2,19 \\
\hline Facão & 1 & und & 2,49 & 2,49 & 5 & 0,50 & 0,00 & 1,69 \\
\hline Martelo & 1 & und & 2,49 & 2,49 & 5 & 0,50 & 0,00 & 1,69 \\
\hline Canivete & 1 & und & 2,49 & 2,49 & 5 & 0,50 & 0,00 & 1,69 \\
\hline Prancheta & 1 & und & 1,89 & 1,89 & 3 & & & 1,26 \\
\hline Rotulador & 1 & und & 13,93 & 13,93 & 3 & & & 9,29 \\
\hline Pincel & 1 & und & 1,00 & 1,00 & 1 & & & 1,00 \\
\hline Lapiseira & 1 & und & 1,99 & 1,99 & 1 & & & 1,99 \\
\hline Caneta & 1 & und & 0,25 & 0,25 & 1 & & & 0,25 \\
\hline Borracha & 1 & und & 0,25 & 0,25 & 1 & & & 0,25 \\
\hline Prego & 1 & $\mathrm{~kg}$ & 1,00 & 1,00 & 1 & & & 1,00 \\
\hline Estaca & 232 & und & 0,25 & 57,71 & 1 & & & 57,71 \\
\hline Tinta & 1 & lata & 3,23 & 3,23 & 1 & & & 3,23 \\
\hline Fita do rotulador & 12 & und & 1,59 & 19,10 & 1 & & & 19,10 \\
\hline Total & & & 83,77 & 160,23 & & 11,98 & 0,05 & 135,96 \\
\hline
\end{tabular}

Amaral et al. (1998), trabalhando com uma equipe de três pessoas, obtiveram um custo de US $\$ 8,80 /$ ha, tendo o salário pago aos funcionários sido responsável por 90\% desse total. Barreto et al. (1993) gastaram US\$5,20/ ha para abertura de picadas.

No presente trabalho, o alto custo verificado foi influenciado diretamente pelo rendimento da abertura de picadas, que, por sua vez, foi uma função das condições gerais da floresta. Um baixo rendimento faz que seja necessário gastar mais tempo para a realização do serviço e, conseqüentemente, aumenta-se o custo com juros, depreciação, alimentação e salários. Outro motivo foi o valor dos salários pagos à equipe. Amaral et al. (1998) gastaram em torno de US\$ 450,00/mês em pagamento aos três membros da equipe, enquanto nesse 
inventário o pessoal recebia US\$747,00/mês, ou 66\% a mais. Considerando que o salário do engenheiro represente mais de $70 \%$ desse valor, a sua eventual substituição por um trabalhador treinado e capaz de dirigir os trabalhos em campo acarretaria uma redução substancial nesse custo. As estimativas de alturas total e comercial com o hipsômetro Vertex em ambiente de mata natural secundária constituíram outro fator que onerou os custos do inventário de prospecção.

\subsubsection{Inventário de prospecção}

Foram gastos no inventário de prospecção, em média, US $\$ 89,43 /$ ha, o que equivale a US $\$ 2,10 / \mathrm{m}^{3}$ de madeira estocada no talhão.

O custo de oportunidade ou juros foi de US\$0,81/ ha. Com os salários foram gastos US $\$ 46,73 /$ ha e com os encargos sociais, US\$27,10/ha, o que representa um custo total com salários de US\$73,83/ha. Com alimentação e administração foram gastos, respectivamente, US\$ 6,20/ha e US\$ 8,13/ha. A soma dos custos com depreciação de equipamentos foi de US $\$ 0,46 /$ ha.

A proporção de cada componente do custo sobre o valor total foi de 82,$61 ; 9,10 ; 6,94 ; 0,86$; e $0,50 \%$, respectivamente, para salários, administração, alimentação, juros e depreciação.

Amaral et al. (1998) obtiveram um custo de US\$9,40/ ha, enquanto Gama Silva e Braz (1993) gastaram apenas US $\$ 1,09 /$ ha para a mesma atividade. Costa et al. (1999) apresentaram um custo de US $\$ 7,53 /$ ha e US $\$ 0,48 / \mathrm{m}^{3}$ de madeira explorável para a realização do inventário.

Assim como foi demonstrado para a abertura de picadas, o baixo rendimento teve forte influência nos custos do inventário de prospecção, principalmente devido à declividade do terreno e ao baixo nível de inclusão $(D A P \geq 20 \mathrm{~cm})$. No presente trabalho foi possível mapear menos de 1 ha por dia, outros levantamentos apresentaram rendimentos 7 a 31 vezes superiores, o que afetou diretamente os valores pagos para a realização de tais mapeamentos.

\section{CONCLUSÃO}

A metodologia de inventário de prospecção em que se utilizou o hipsômetro Vertex, proposta para este trabalho, mostrou-se exequível para a Floresta Estacional Semidecidual Submontana. Porém, algumas ressalvas devem ser feitas. O baixo rendimento das operações, que resultou em custos elevados, foi ocasionado diretamente pelas características dessa fitofisionomia e pelas peculiaridades do relevo onde ela se encontra. O sub-bosque denso e infestado por cipós, a necessidade de inventariar indivíduos de menor diâmetro e a declividade acentuada são algumas dessas características.

Quadro 2 - Lista dos equipamentos e do material de consumo utilizados no inventário de prospecção do talhão de exploração no 8 , com os respectivos valores de compra $\left(\mathrm{V}_{\mathrm{c}}\right)$ e revenda $\left(\mathrm{V}_{\mathrm{r}}\right)$, vida útil $(\mathrm{n})$, depreciação $\left(\mathrm{D}_{\mathrm{ha}}\right)$ e investimento médio anual (IMA). Valores em US\$

Table 2 - List of the equipment and consumption material used in the no. 8 logging stand prospection survey, with their respective purchase (Vc) and resale (Vr) values, shelf life (n), depreciation (Dha) and mean annual investiment (IMA). Values in US\$

\begin{tabular}{|c|c|c|c|c|c|c|c|c|}
\hline Equipamento & Quantidade & Unidade & Preço & $\mathrm{V}_{\mathrm{c}}$ & $\mathrm{n}$ & $\mathrm{V}_{\mathrm{r}}$ & D ha & IMA \\
\hline Trena & 2 & und & 37,00 & 74,00 & 5 & 14,80 & 0,06 & 50,32 \\
\hline Distanciômetro Ve & ertex 1 & und & 1985,00 & 1985,00 & 20 & 397,00 & 0,38 & 1230,70 \\
\hline Podão & 1 & und & 35,82 & 35,82 & 10 & 7,16 & 0,01 & 22,93 \\
\hline Facão & 1 & und & 2,49 & 2,49 & 5 & 0,50 & 0,00 & 1,69 \\
\hline Martelo & 1 & und & 2,49 & 2,49 & 5 & 0,50 & 0,00 & 1,69 \\
\hline Canivete & 1 & und & 2,49 & 2,49 & 5 & 0,50 & 0,00 & 1,69 \\
\hline Prancheta & 1 & und & 1,89 & 1,89 & 3 & & & 1,26 \\
\hline Rotulador & 1 & und & 13,93 & 13,93 & 3 & & & 9,29 \\
\hline Fita métrica & 2 & und & 0,75 & 1,49 & 1 & & & 1,49 \\
\hline Lapiseira & 1 & und & 1,99 & 1,99 & 1 & & & 1,99 \\
\hline Caneta & 1 & und & 0,25 & 0,25 & 1 & & & 0,25 \\
\hline Borracha & 1 & und & 0,25 & 0,25 & 1 & & & 0,25 \\
\hline Prego & 1 & $\mathrm{~kg}$ & 1,00 & 1,00 & 1 & & & 1,00 \\
\hline Fita do rotulador & 12 & und & 1,59 & 19,10 & 1 & & & 19,10 \\
\hline Fita crepe & 1 & und & 1,39 & 1,39 & 1 & & & 1,39 \\
\hline Total & & & & $2.143,58$ & & 420,46 & 0,45 & $1.345,04$ \\
\hline
\end{tabular}


O rigor exigido para determinação das coordenadas X e Y, com a utilização de trenas e do distanciômetro digital, também contribuiu para o baixo rendimento do inventário. Por não se dispor de métodos de inventário de prospecção para a Floresta Estacional Semidecidual, foi necessário lançar mão de comparações com outros inventários descritos na literatura, que, por sua vez, foram realizados em outra fitofisionomia e com métodos diferentes.

\section{REFERÊNCIAS BIBLIOGRÁFICAS}

AMARAL, P. et al. Florestas para sempre: um manual para a produção de madeira na Amazônia. Belém: IMAZON, 1998. 137p.

BARRETO, P.G.; UHL, C.; YARED, J. O potencial de produção sustentável de madeira em Paragominas - PA; na Amazônia Oriental: considerações ecológicas e econômicas. In: CONGRESSO FLORESTAL PAN-AMERICANO, 1; CONGRESSO FLORESTAL BRASILEIRO, 7., 1993, Curitiba, PR. Anais... Curitiba: 1993. p.387-392.

BARRos, A. C.; VERÍSSIMO, A. A expansão da atividade madeireira na Amazônia: Impactos e perspectivas para o desenvolvimento do setor florestal no Pará. Belém: IMAZON - Instituto do Homem e meio Ambiente da Amazônia, 1996. $167 \mathrm{p}$.

BODEGON, A. J.; Van GRAAF, N. R. Sistema Celos de Manejo. Wageningen: Centro Nacional de Referência para a Natureza, Florestas e Paisagem, 1994. 58p.

CARVAlho, J. O. P. Structure and dynamics of a logger over Brazilian Amazonian rain forest. 1992. 215f. Thesis (Ph.D.) - University of Oxford, Oxford, 1992.

FUNDAÇÃO CENTRO TECNOLÓGICO DE MINAS GERAIS - CETEC. Determinação de equações volumétricas aplicáveis ao manejo sustentado de florestas nativas no Estado de Minas Gerais e outras regiões do País. Belo Horizonte: 1995. 295p.

R. Árvore, Viçosa-MG, v.29, n.1, p.65-75, 2005
COSTA, D. H. M. et al. Potencial madeireiro de floresta densa no município de Moju, Estado do Pará. In: SIMPÓSIO SILVICULTURANA AMAZÔNIA ORIENTAL: Contribuições do projeto EMBRAPA/DFID, 1999, Belém. Anais... Belém: 1999. p.138-141.

EMPRESA BRASILEIRA DE PESQUISA AGROPECUÁRIA - EMBRAPA-CPATU. A pesquisa florestal da EMBRAPA/CPATU na região do Tapajós. In: ENCONTRO SOBRE PESQUISA FLORESTAL NA REGIÃO DO TAPAJÓS. Belém: 1991. p.11-28.

FARO, C. Elementos de engenharia econômica. 3 ed. São Paulo: Atlas, 1979, 328p.

FUPEF. Inventário comercial de um bloco de exploração na Floresta Nacional do Tapajós. Curitiba: Fundação de Pesquisas Florestais do Paraná, 1983. 234p. (Relatório Técnico).

GAMA SILVA, Z.A.G.P.; BRAZ, E.M. Identificação do custo de produção do manejo florestal sustentado e seus reflexos nas serrarias do Estado do Acre. In: CONGRESSO FLORESTAL PAN-AMERICANO, 1., CONGRESSO FLORESTAL BRASILEIRO, 7., 1993, Curitiba. Anais... Curitiba: 1993. p.363-366.

HIRSCHFELD, H. Engenharia econômica e análise de custos. 5 ed. São Paulo: ATLAS, 1992. 465p.

IBAMA. Instrução normativa no 4 , de 4 de março de 2002. Dispõe sobre o manejo florestal sustentável de uso múltiplo na Amazônia Legal. (http://ibama.gov.br).

GOMES, A. P. C.; SOUZA, A. L.; MEIRA NETO, J.A.A. Alteração estrutural de uma área florestal explorada convencionalmente na bacia do Paraíba do Sul, Minas Gerais, nos domínios de floresta atlântica. Revista Árvore, v.28, n.3, p.407-417, 2004.

MACHADO, S. A. Complete enumeration forest inventory versus cluster sampling method applied in the Amazonic rain forest. Floresta, v. 17, n..1/ 2, p.122-130, 1988. 
Minas Gerais. Portaria no 054 , de 25 de agosto de 1997. Belo Horizonte: IEF, 1997. $19 \mathrm{p}$.

NAUTIVAL, J.C. Forest economics: principles and applications. Toronto: Canadian Scholar's Press, 1988. 581 p.

REZENDE, J.L.P.; OLIVEIRA, A.D. Análise econômica e social de projetos florestais. Viçosa: Universidade Federal de Viçosa, 2001. 389 p.

SILVA, J.N.M. The behaviour of the tropical rain forest of the Brazilian Amazon after logging. Oxford: University of Oxford, 1989. 302p. Thesis (Ph.D.) - University of Oxford, Oxford, 1989.

SILVA, J.N.; LOPES, J.C. A. Inventário florestal contínuo em florestas tropicais: a metodologia utilizada pela EMBRAPA-CPATU na amazônia brasileira. Belém: EMBRAPACPATU, 1984. 39p.
SILVA, M.L.; JACOVINE, L.A.G.; VALVERDE, S.R. Economia florestal. Viçosa: Universidade Federal de Viçosa, 2002. 178p.

SPEIDEL, G. Economia florestal. Curitiba: Universidade Federal do Paraná, 1966. 167p.

SUPERINTENDÊNCIAPARAO

DESENVOLVIMENTO DAAMAZÔNIA - SUDAM. Estudo da viabilidade técnicoeconômica da exploração mecanizada em floresta de terra firme, região de Curuá-Una. Belém: 1978. 137p.

VERÍSSIMO, A. et al. Impactos sociais, econômicos e ecológicos da exploração seletiva de madeiras numa região de fronteira na Amazônia Oriental: o caso da Tailândia. In: BARROS, A.C.; VERÍSSIMO, A., (Eds.) A expansão da atividade madeireira na Amazônia: impactos e perspectivas para o desenvolvimento do setor florestal no Pará. Belém: Instituto do Homem e Meio Ambiente da Amazônia, 1996. p.9-43. 
